\title{
Quadriceps Muscle Oxygenation during a Maximum Stress Test in Middle-Aged Athletes
}

\author{
María-José Paredes-Ruiz', María Jódar-Reverte', Vicente Ferrer-Lopez', Ignacio Martínez- \\ González-Moro'
}

Affiliations: 'University of Murcia, University Institute for Researching in Aging, Research Group: Physical Exercise and Human Performance, Murcia, Spain

Correspondence: I. Martínez-González-Moro, University of Murcia, Faculty of Medicine, 30100 Campus Espinardo, Murcia, Spain. E-mail: ignaciomgm@um.es

ABSTRACT Determining oxygen muscle saturation $\left(\mathrm{SmO}_{2}\right)$ using near-infrared spectroscopy (NIRS) is an emerging technique that is increasingly used in sports science; therefore, it is necessary to know its results in different population groups. We analysed it in a group of recreational participants in Nordic Walking. The purpose of this research was to analyse the $\mathrm{SmO}_{2}$ values obtained at various times from testing in a group of athletes over 45. Thirty athletes (18 males) with a mean age of 51.3 years completed a maximal exercise testing in treadmill according to a modified Bruce protocol on a ramp. The electrocardiogram was continuously monitored. We measured $\mathrm{VO}_{2} \max$ (Metalyzer 3B). In addition, we placed a Humon Hex device on the right thigh to measure quadriceps oxygenation. Heart rate, $\mathrm{VO}_{2}$, and $\mathrm{SmO}_{2}$ ratios were obtained based on the exercise intensity. We obtained a $\mathrm{SmO}_{2}$ at startup of 63.3\%, standard deviation (SD) 9.2\%; $\mathrm{SmO}_{2}$ declined $61.8 \%$, SD $11.4 \%$; $\mathrm{SmO}_{2}$ in $\mathrm{VO}_{2} \max 57.4 \%$ SD $10.2 \%$ and $\mathrm{SmO}_{2} 5$ minutes after starting recovery $72.5 \%$ SD7.9\%. There was a relationship between ventilatory thresholds and variations in $\mathrm{SmO}_{2}$. There were no significant differences between the sexes. We could conclude that the minimum values of $\mathrm{SmO}_{2}$ were related to the $\mathrm{VO}_{2}$ max. During the recovery phase, the values were higher than at rest. The information obtained could be used to control and plan the training.

KEY WORDS nordic walking, muscle oxygenation, maximal exercise testing

$@$ MJSSMontenegro

QUADRICEPS MUSCLE OXYGENATION

http://mjssm.me/?sekcija=article\&artid=203

\section{Introduction}

Haemoglobin is the oxygen transport protein from the lungs to the muscles. Oxygen intake is a key factor for muscle metabolism, maintaining physical activity and athletic performance (Hearris, Hammond, Fell, \& Morton, 2018). In sports science, there are several methods used to evaluate muscle metabolism and plan training sessions, some of which are based on the measurement of lactic acid in capillary blood and others on the study of spirometric variables related to maximal oxygen uptake $\left(\mathrm{VO}_{2} \max \right)$ (Hawkins, Raven, Snell, Stray-Gundersen \& Levine, 2007) and determining ventilatory thresholds (Lam \& Ravussin, 2016). Recently, measurements of oxygen muscle saturation $\left(\mathrm{SmO}_{2}\right)$ are also being used (Crum, O'Connor, Van Loo, Valckx, \& Stannard 2017).

$\mathrm{SmO}_{2}$ is obtained non-invasively with Near-Infrared Spectroscopy (NIRS) via the placement of skin devices (Hamaoka \& McCully, 2019). This technique allows obtaining immediately, on a screen, the percentage of muscle saturation of oxygen; the current devices comprise a small receiver that is placed with a belt surrounding the body segment to be assessed. The most commonly used location is in the thigh in order to measure the $\mathrm{SmO}_{2}$ of the quadriceps (vastus lateralis) (Grassi \& Quaresima, 2016). The data are sent to a computer application that can be installed on a watch, smartphone, or tablet that can be consulted by the athlete or researcher. The information received enables adapting the intensity of the exercise according to a specific objective, similar to what is done with a heart rate monitor (Ferrrari, Muthalib, \& Quaresima, 2011).

NIRS technology for measuring the $\mathrm{SmO}_{2}$ is validated and has been used primarily by elite athletes (Chang et al., 2019), but there is little evidence of its use in older people who practice physical activity to improve their health (Gepner, Wells, \& Gordon, 2019). For physical exercise to produce benefits, it is known that it is necessary to be 
performed with adequate frequency and intensity (Murphy, Lahart, Carlin, \& Murtagh, 2019). Therefore, the control of this intensity of physical activity and the possibility of regulating it according to the characteristics of each person is essential to increase the benefits of training (Wewege, Thom, Rye, \& Parmenter, 2018).

The most recommended physical exercise for the elderly is walking for several hours, several days a week, with moderate intensity (Slaght, Sénéchal, Hrubeniuk, Mayo, \& Bouchard, 2017). A modification of the usual walk is "Nordic walking" (NW), which is a specific sport discipline with its own rules and competitions (Padulo et al., 2018). In this sport, poles and a specific technique for walking are used, maintaining an upright posture and increasing the speed and intensity of effort (Mocera, Aquilino, \& Somà, 2018). NW is increasingly recommended for older people because of its relative ease, accessibility and health effects (Tschentscher, Niederseer, \& Niebauer, 2013). If NW practitioners monitor the pace of walking, depending on their specific abilities, they improve the effects of exercise (Takeshima et al., 2013).

Measuring $\mathrm{SmO}_{2}$ can be a good way of controlling the intensity of exercise and adapting it to the needs of the person (Wilkinson et al., 2019). To accomplish this, it would be interesting to have studies that confirm the usefulness of $\mathrm{SmO}_{2}$, relating it to the data obtained with traditional techniques of performance assessment, assuming the peculiar responses of these subjects. Thus, the objective of our work is to analyse the values of $\mathrm{SmO}_{2}$ obtained at various times in a maximal exercise stress test in a group of recreational athletes over 45 years old who practice NW.

\section{Methods}

The study population was 30 adults over 45 years old, recreational athletes of the clubs "Nordic Walking Murcia" and "Marcha Nórdica Costa Blanca Elx " (Spain), with at least two years of experience in NW (mean $2.9 \pm 1.0$ years). Participants walked three days a week, about $10 \mathrm{~km}$ each day.

All participants provided written, informed consent for their participation in the study. The inclusion criteria were to have a minimum of one year of experience, excluding those suffering from illnesses, injuries, or deficiencies that prevented them from taking the stress test. The study was conducted according to the principles of the Declaration of Helsinki and was approved by the Research Ethics Commission of the University of Murcia.

First, cardiovascular examinations at rest were performed with the athletes in supine decubitus, assessing cardiac auscultation, blood pressure, and electrocardiogram (EKG). The electrodes were maintained to collect the EKG trace throughout the stress test. Heart rate (HR) and EKG recording were obtained with a Cube ${ }^{\circ}$ cardioline electrocardiograph. Subsequently, a Humon $\mathrm{Hex}^{\oplus}$ device was placed on the thigh of the dominant side, on the vastus lateralis (Figure 1). To display the information of the $\mathrm{SmO}_{2}$, exercise time and heart rate (HR), the Humon $\mathrm{Hex}^{\bullet}$ was synchronized with a tablet with the Humon app.

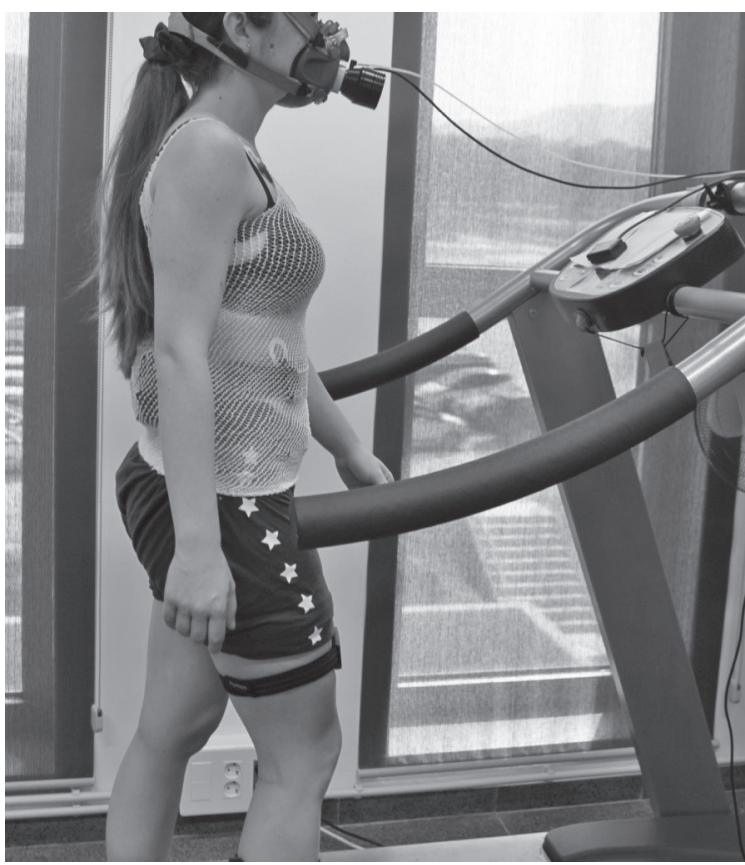

FIGURE 1. Start of the test. Humon Hex ${ }^{\oplus}$ placed on right thigh

The stress test was performed on a treadmill (model run $7411^{\circ}$ ) with a modified Bruce ramp protocol. The test ended when the subject could no longer run and gestured with his hand and began the recovery phase by slowing down ( 3 minutes to $4 \mathrm{~km} /$ hour). The tests were considered to be maximum and valid when $85 \%$ of the theoretical maximum heart rate (220-age) was exceeded, and the respiratory ratio (RER) was greater than 1.15 (Howley 1995).

During the stress test, the subjects breathed through a mask connected to the gas analyser (Metalyzer $3 \mathrm{~b}^{\circ}$, Cortex). All gas exchange parameters were measured during breathing and averaged every 30 seconds. The method used for determining $\mathrm{VO}_{2}$ max was to reach the plateau of oxygen consumption (Fletcher 2009). All 
tests were carried out under similar environmental conditions.

The values of $\mathrm{SmO}_{2}$ were obtained from the curves $\mathrm{SmO}_{2}$ /exercise time (Figure 2) provided by the Humon Hex app ${ }^{\oplus}$, selecting the data for the following phases: 1) prior to the exercise; (2) decline phase: at the time of the sharp decline or descent of the $\mathrm{SmO}_{2}$ (Humon $\mathrm{Hex}^{\oplus}$ indicates this situation with a change in colour (orange); 3) the maximum descent that coincides with the maximum exercise intensity and with the $\mathrm{VO}_{2} \max$ ); and 4) recovery phase: after the exercise, when the normal values are retrieved (indicated by another colour change on the graph, from blue to green).

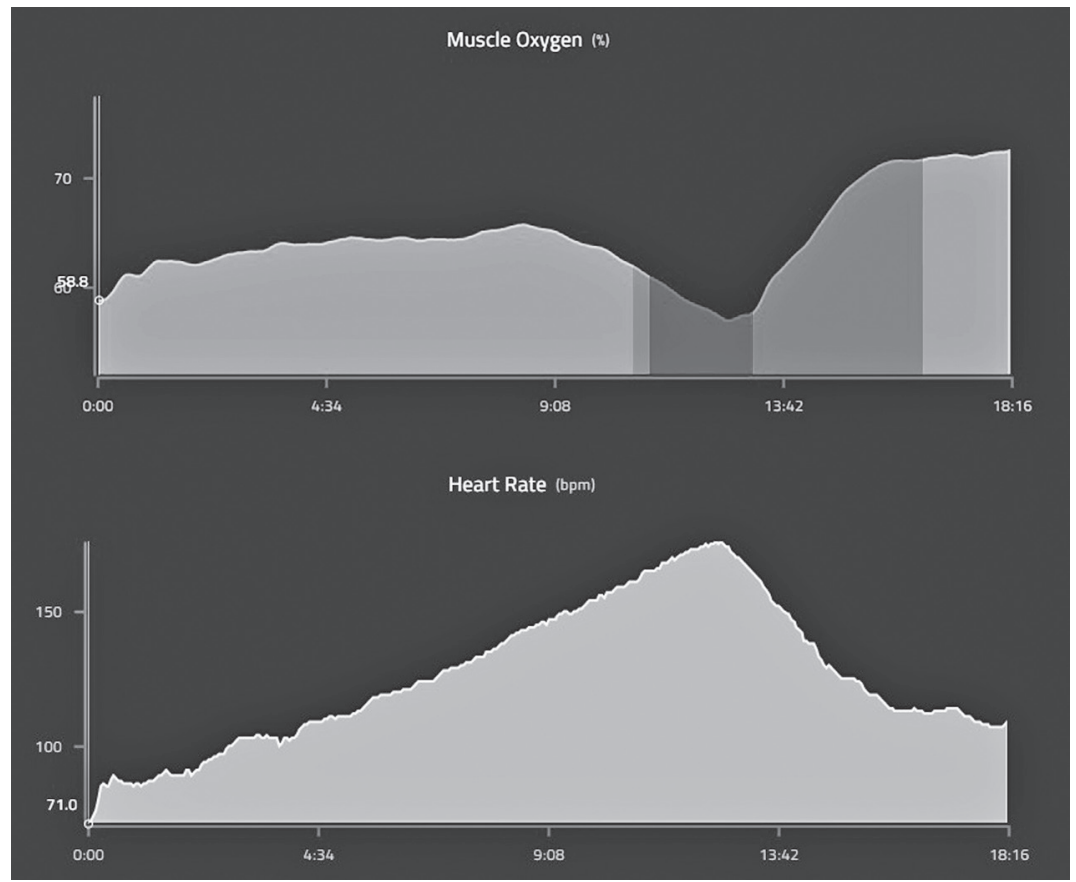

FIGURE 2. Heart rate and $\mathrm{SmO}_{2}$ /exercise time curves

All statistical analyses were conducted using SPSS software version 24.0 (Chicago, IL, USA). Quantitative variables have been described with mean, standard deviation $(\mathrm{SD})$ and coefficient of variation $(\mathrm{CV}=\mathrm{SD} / \mathrm{mean}$ $\times 100)$ and qualitative by absolute frequency and percentage. The normal distribution of the variables was checked by the Shapiro-Wilk test, and the equal variances using the Levene test. Comparison of means of independent variables and intergroups (men and women) was performed using the t-student test; a paired samples t-test was used to compare the means of related variables. The relationship between variables was studied using Pearson's correlation analysis. A level of significance of $\mathrm{p}<0.05$ was considered.

Results

In Table 1, the characteristics of the population separated by sex (18 male and 12 females) are shown; only differences between men and women in size, weight, and $\mathrm{VO}_{2}$ max are noted. Coefficients of variation indicate that the population is homogeneous.

\begin{tabular}{|c|c|c|c|c|c|}
\hline & Gender & Mean & $\begin{array}{l}\text { Standard } \\
\text { deviation }\end{array}$ & $\begin{array}{c}\text { Variation } \\
\text { Coefficient (\%) }\end{array}$ & $\begin{array}{c}\text { Significance ( } p \\
\text { value) }\end{array}$ \\
\hline \multirow{2}{*}{ Age (years) } & Males & 50.06 & 6.64 & 13.3 & \multirow{2}{*}{0.074} \\
\hline & Females & 53.75 & 2.18 & 4.1 & \\
\hline \multirow{2}{*}{ Height (m) } & Males & 1.78 & 0.05 & 2.8 & \multirow{2}{*}{0.000} \\
\hline & Females & 1.65 & 0.04 & 2.4 & \\
\hline \multirow{2}{*}{ Weight (Kg) } & Males & 81.08 & 8.99 & 11.1 & \multirow{2}{*}{0.000} \\
\hline & Females & 67.31 & 7.16 & 10.6 & \\
\hline \multirow{2}{*}{$\mathrm{BMI}\left(\mathrm{Kg} / \mathrm{m}^{2}\right)$} & Males & 25.52 & 2.71 & 10.6 & \multirow{2}{*}{0.423} \\
\hline & Females & 24.72 & 2.54 & 10.3 & \\
\hline \multirow{2}{*}{ \%HRmax prediction } & Males & 99.19 & 7.93 & 8.0 & \multirow{2}{*}{0.477} \\
\hline & Females & 96.79 & 10.29 & 10.6 & \\
\hline \multirow{2}{*}{$\mathrm{VO}_{2} \max (\mathrm{ml} / \mathrm{Kg} / \mathrm{min})$} & Males & 33.50 & 8.54 & 25.5 & \multirow{2}{*}{0.024} \\
\hline & Females & 27.08 & 4.52 & 16.7 & \\
\hline
\end{tabular}

Note. HR: Heart rate; SmO2 muscle oxygen saturation; VO2: oxygen consumption. 
The comparison between groups by gender of $\mathrm{SmO}_{2}$ and heart rate in each of the four stages in which the evolution of $\mathrm{SmO}_{2}$ has been divided during the effort shows no differences between males and females (Table 2). Likewise, the percentage of HR at the time of the decline from the maximum reached also shows no differences between sexes. Males show slightly higher values at the onset of decline; there are also no differences between the sexes in the $\mathrm{SmO}_{2}$ in maximum effort and recovery.

\begin{tabular}{|c|c|c|c|c|c|}
\hline & Gender & Mean & $\begin{array}{l}\text { Standard } \\
\text { deviation }\end{array}$ & $\begin{array}{c}\text { Variation } \\
\text { Coefficient (\%) }\end{array}$ & $\begin{array}{c}\text { Significance } \\
(p \text {-value })\end{array}$ \\
\hline \multirow{2}{*}{$\begin{array}{c}\% \mathrm{SmO}_{2} \text { Prior to the } \\
\text { exercise }\end{array}$} & Males & 62.73 & 7.42 & 11.8 & \multirow{2}{*}{0.665} \\
\hline & Females & 64.27 & 11.86 & 18.5 & \\
\hline \multirow{2}{*}{$\begin{array}{c}\% \mathrm{SmO}_{2} \text { Decline } \\
\text { phase }\end{array}$} & Males & 63.11 & 9.10 & 14.4 & \multirow{2}{*}{0.432} \\
\hline & Females & 59.47 & 15.17 & 25.5 & \\
\hline \multirow{2}{*}{$\begin{array}{c}\% \mathrm{SmO}_{2} \text { Maximum } \\
\text { exercise }\end{array}$} & Males & 59.51 & 9.27 & 15.6 & \multirow{2}{*}{0.161} \\
\hline & Females & 53.97 & 11.20 & 20.8 & \\
\hline \multirow{2}{*}{$\begin{array}{c}\% \mathrm{SmO}_{2} \text { Recovery } \\
\text { phase }\end{array}$} & Males & 71.54 & 7.98 & 11.2 & \multirow{2}{*}{0.413} \\
\hline & Females & 74.01 & 7.93 & 10.7 & \\
\hline \multirow{2}{*}{$\begin{array}{l}\mathrm{HR} \text { (lat/min) } \\
\text { Prior to the exercise }\end{array}$} & Males & 75.83 & 10.23 & 13.5 & \multirow{2}{*}{0.328} \\
\hline & Females & 72.33 & 8.05 & 11.1 & \\
\hline \multirow{2}{*}{$\begin{array}{l}\text { HR (lat/min) } \\
\text { Decline phase }\end{array}$} & Males & 143.11 & 29.50 & 20.6 & \multirow{2}{*}{0.445} \\
\hline & Females & 134.60 & 24.28 & 18.0 & \\
\hline \multirow{2}{*}{$\begin{array}{l}\mathrm{HR}(\mathrm{I} / \mathrm{m}) \text { Maximum } \\
\text { exercise }\end{array}$} & Males & 169.20 & 14.22 & 8.4 & \multirow{2}{*}{0.180} \\
\hline & Females & 160.8 & 18.35 & 12.1 & \\
\hline \multirow{2}{*}{$\begin{array}{c}\text { HR (lat/min) } \\
\text { Recovery phase }\end{array}$} & Males & 120.11 & 18.04 & 15.0 & \multirow{2}{*}{0.174} \\
\hline & Females & 111.00 & 16.68 & 15.0 & \\
\hline \multirow{2}{*}{$\begin{array}{l}\% \mathrm{HR} \text { decline/HR } \\
\text { maximum exercise }\end{array}$} & Males & 83.83 & 13.51 & 16.11 & \multirow{2}{*}{0.740} \\
\hline & Females & 82.17 & 10.55 & 12.84 & \\
\hline \multirow{2}{*}{$\begin{array}{l}\text { Minutes to decline } \\
\text { phase }\end{array}$} & Males & 8.63 & 3.16 & 36.58 & \multirow{2}{*}{0.072} \\
\hline & Females & 6.56 & 1.98 & 30.21 & \\
\hline \multirow{2}{*}{$\begin{array}{l}\text { Minutes to } \\
\text { maximum exercise }\end{array}$} & Males & 11.62 & 2.97 & 25.54 & \multirow{2}{*}{0.166} \\
\hline & Females & 10.04 & 1.98 & 19.72 & \\
\hline \multirow{2}{*}{$\begin{array}{l}\text { Minutes to recovery } \\
\text { phase }\end{array}$} & Males & 5.31 & 3.06 & 57.61 & \multirow{2}{*}{0.321} \\
\hline & Females & 4.12 & 2.13 & 51.73 & \\
\hline
\end{tabular}

Note. HR: Heart ratio; $\mathrm{SmO}_{2}$ muscle oxygen saturation; $\mathrm{VO}_{2}$ : Oxygen consumption.

Figure 3 shows the evolution of the $\mathrm{SmO}_{2}, \mathrm{VO}_{2}$, and $\mathrm{HR}$ throughout the stress test. $\mathrm{VO}_{2}$ and $\mathrm{HR}$ increase in the early stages and decrease during the recovery phase; the situation is reversed with $\mathrm{SmO}_{2}$.

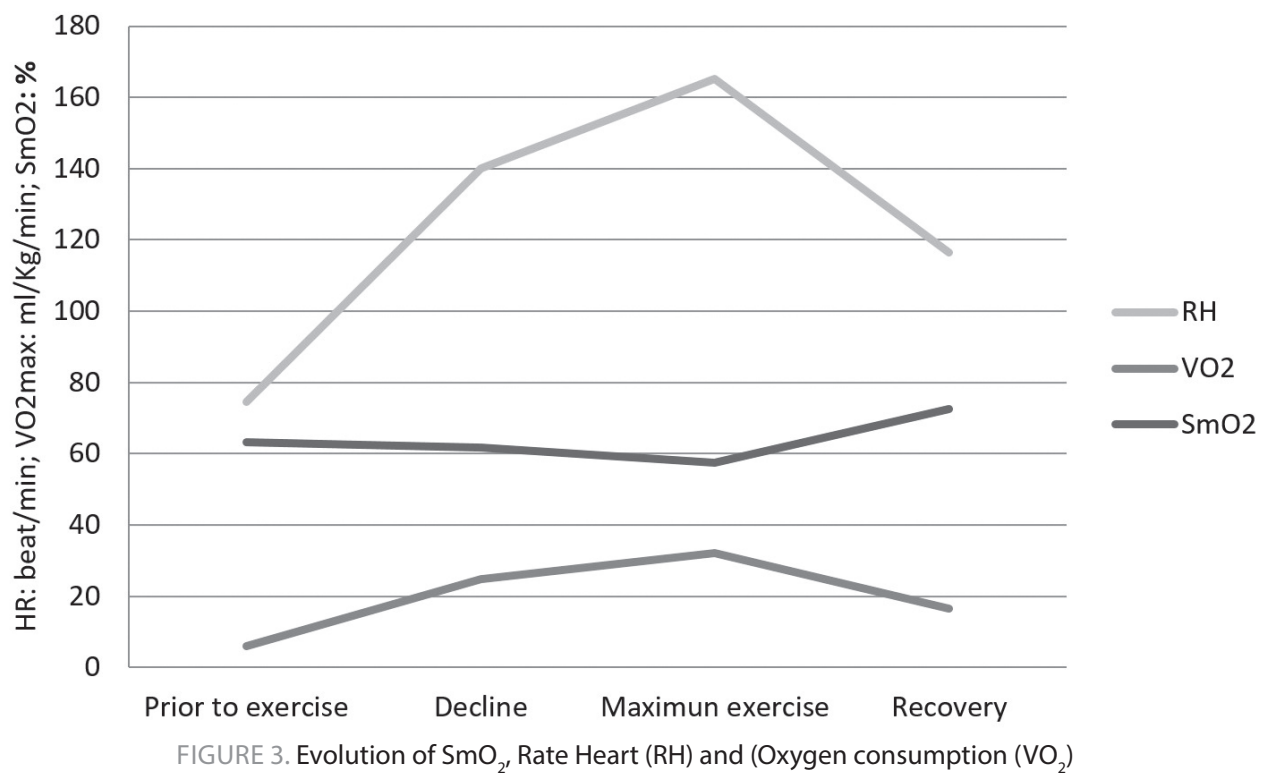


When the $\mathrm{SmO}_{2}$ with RER, HR, and $\mathrm{VO}_{2}$ is correlated in each of the phases, only a significant correlation is observed between all of them in the recovery phase. With the maximum effort, $\mathrm{SmO}_{2}$ is correlated with the RER; higher RER correlates with lower $\mathrm{SmO}_{2}$ (Table 3).

\begin{tabular}{ccccc}
\multicolumn{7}{c}{ TABLE 3. Correlations between $\mathrm{SmO}_{2}$ and ergometry values } \\
& $\mathrm{SmO}_{2}$ Decline & $\mathrm{SmO}_{2}$ maximum exercise & $\begin{array}{c}\mathrm{SmO}_{2} \\
\text { Recovery phase }\end{array}$ \\
\hline \multirow{2}{*}{$\mathrm{RER}$} & Pearson correlation & -0.360 & -0.454 & -0.789 \\
& Significance ( $\mathrm{p}$ value) & 0.065 & $0.039^{*}$ & $0.000^{*}$ \\
$\mathrm{HR}$ & Pearson correlation & -0.125 & -0.021 & -0.391 \\
& Significance ( $\mathrm{p}$ value) & 0.533 & 0.913 & $0.033^{*}$ \\
$\mathrm{VO}_{2}$ & Pearson correlation & -0.266 & -0.193 & -0.486 \\
& Significance ( $\mathrm{p}$ value) & 0.180 & 0.315 & $0.006^{*}$ \\
\hline
\end{tabular}

Note. RER: Respiratory Exchange Ratio (Respiratory Quotient); $\mathrm{HR}$ : Heart rate; $\mathrm{SmO}_{2}$ muscle oxygen saturation; $\mathrm{VO}_{2}$ : oxygen consumption; ${ }^{*} p<0.05$.

In contrast, the correlations between pre-exercise $\mathrm{SmO}_{2}$ and the other saturation measures show significant values, with $\mathrm{SmO}_{2}$ decline phase $(\mathrm{r}=0.875 ; \mathrm{p}<0.000)$; with $\mathrm{SmO}_{2}$ in the maximum effort $(\mathrm{r}=0.851 ; \mathrm{p}<0.000)$ and with $\mathrm{SmO}_{2}$ in the recovery phase $(\mathrm{r}=0.816 ; \mathrm{p}<0.000)$.

There are significant differences between $\mathrm{SmO}_{2}$ prior to the test and that obtained in the maximum effort ( $\mathrm{t}$ 6.061; $\mathrm{p}<0.000)$, also with the $\mathrm{SmO}_{2}$ of the recovery phase $(\mathrm{t}-9.350 ; \mathrm{p}<0.000)$; but there are differences with the $\mathrm{SmO}_{2}$ obtained at the beginning of the decline (t-1.995; $\left.\mathrm{p}-0.056\right)$.

The $\mathrm{SmO}_{2}$ at the time of decline does not maintain a correlation with the percentage of the maximum HR reached $(\mathrm{r}=-0.34 ; \mathrm{p}=0.868)$, nor with the exercise time to that point $(\mathrm{r}=0.048 ; \mathrm{p}=0.813)$.

\section{Discussion}

Measuring $\mathrm{SmO}_{2}$ using NIRS devices is a recently used technique in the assessment of physical condition. For this reason, we have done this work to provide new knowledge about its use and its results. We used a Humon $\mathrm{Hex}^{\otimes}$ device in a population of subjects over 45 years of age, practitioners of Nordic Walking, to measure the $\mathrm{SmO}_{2}$ of the quadriceps while performing a stress test on a treadmill, the validity of this device has been previously verified by Farzam, Starkweather, and Franceschini (2018). We have divided the stress test into four phases and compared the values of men and women without entering differences between the sexes.

The stress test has been performed with a modified Bruce ramp protocol because it manages to reach the exhaustion of the subject without having to run. Furthermore, this test is more similar to NW than the protocols based on speed increase (Pellegrini, 2018).

Most studies with NIRS have been done with young male athletes, while we have studied middle-aged adults, comparing both sexes, allowing us to increase the information available on $\mathrm{SmO}_{2}$ (Seshadri, et al., 2019). Our results indicate, as in the study of Wilkinson et al. (2019), that as exercise intensity increases, a decrease in $\mathrm{SmO}_{2}$ occurs, to a point at which an inflection appears. This is shown in the tablet graphics with a colour change (Humon, 2020). Other authors relate this inflection to the ventilatory threshold (Karatzano et al., 2010), although they indicate that there is a great individual variability due to fat percentage, age, and physical activity (Zwaard et al., 2016).

We have also found that the exercise time in which this change occurs is different among subjects, showing a medium coefficient of variation (30-36\%), but without significant differences between the sexes; this could be related to the physical condition of each person (Takaishi et al., 2002).

From the tipping point, the $\mathrm{SmO}_{2}$ continues to decrease, as the intensity of the exercise progresses, reaching exhaustion. We have seen that the minimum value of $\mathrm{SmO}_{2}$ also appears at the time when the $\mathrm{VO}_{2} \max$ is achieved. Inglis, Iannetta \& Murias (2017) state that this situation would not indicate the upper limit of $\mathrm{O}_{2}$ extraction and that there could be a reserve area. With the maximum exercise, our subjects had values higher than those cited by Yamamoto et al. (2014).

At the beginning of recovery, after the point of maximum effort, the heart rate begins to drop, at which point it is observed that $\mathrm{SmO}_{2}$ increases gradually, reaching values higher than the initial ones. This effect is similar to the "super-compensation principle" of training (Doering, Coxa, Aretac, \& Coffeya, 2019). Not all authors value this phase of recovery (Contreras Briceño et al., 2019); however, we think it may be interesting when using the Humon $\mathrm{Hex}^{\oplus}$ device to conduct training and schedule the return to calm.

One limitation of this work is that it has been done on a laboratory test in which participants were not able to use the poles and is, therefore, not fully comparable to the actual activity of the NW.

The usefulness of this study is the applicability of the use of the Humnon Hex device in the training of Nordic walking practitioners. They can adjust the intensity of their effort to the signals received and avoid depletion, 
decreasing intensity when $\mathrm{SmO}_{2}$ values reach the tipping point. The advantage of using the device instead of $\mathrm{VO}_{2} \mathrm{max}$ is that there is no need to pre-perform a stress test to regulate exercise intensity.

We conclude that there are no differences between the sexes. The evolution of $\mathrm{SmO}_{2}$ is opposite to that of heart rate and oxygen consumption, decreasing during exercise and increasing in recovery.

\section{Acknowledgements}

The authors would like to thank the clubs "Nordic Walking Murcia" and "Marcha Nórdica Costa Blanca Elx".

\section{References}

Chang, S. C., Adami, A., Lin HC, Lin, Y. C., Chen, C. P., Fu, T. C., ... Huang, S. C. (2019). Relationship between maximal incremental and high-intensity interval exercise performance in elite athletes. bioRxiv, 856237. Retrieved 11/30, 2019, from https://www.biorxiv.org/content/10.1101/856237v1

Contreras-Briceño, F., Espinosa-Ramirez, M., Hevia, G., Llambias, D., Carrasco M., Cerda, F., ... Viscor, G. (2019). Reliability of NIRS portable device for measuring intercostal muscles oxygenation during exercise. Journal of Sports Sciences, 37(23), 2653-2659. doi: 10.1080/02640414.2019.1653422

Crum, E. M., O'Connor, W. J., Van Loo, L., Valckx, M. \& Stannard, S. R. (2017). Validity and reliability of the Moxy oxygen monitor during incremental cycling exercise. European Journal of Sport Science, 17(8), 1037-1043. doi: 10.1080/17461391.2017.1330899

Doering, T. M., Coxa, G. R., Aretac, J. L., \& Coffeya,V. G. (2019). Repeated muscle glycogen supercompensation with four days recovery between exhaustive exercise. Journal of Science and Medicine in Sport, 22, 907911. doi: 10.1016/j.jsams.2019.03.009

Farzam, P., Starkweather, Z., \& Franceschini, M. A. (2018). Validation of a novel wearable, wireless technology to estimate oxygen levels and lactate threshold power in the exercising muscle. Physiological Reports, 6 (7), e13664. doi: 10.14814/phy2.13664

Ferrari, M., Muthalib, M., \& Quaresima, V. (2011). The use of near-infrared spectroscopy in understanding skeletal muscle physiology: recent developments. Philosophical Transactions of Royal Society A, 369: 45774590. doi: $10.1098 /$ rsta.2011.0230

Fletcher, J. R., Esau, S. P., \& MacIntosh, B. R. (2009) . Economy of running: beyond the measurement of oxygen uptake. Journal Applied Physiology, 107, 1918-1922. doi: 10.1152/japplphysiol.00307.2009

Gepner, Y., Wells, A. J., Gordon, J. A., Arroyo, E., Varanoske, A. N., Coker, N. A. ... Hoffmann, J.R., (2019). Differences in muscle oxygenation between young and middle-aged recreationally active men during high-volume resistance exercise. Kinesiology. 51(1), 3-11. doi: 10.26582/k.51.1.4

Grassi, B., \& Quaresima, V. (2016). Near-infrared spectroscopy and skeletal muscle oxidative function in vivo in health and disease: a review from an exercise physiology perspective. Journal of Biomedical Optics, 21(9): 091313. doi: 10.1117/1.JBO.21.9.091313.

Hamaoka, T. \& McCully, K. K. (2019). Review of early development of near-infrared spectroscopy and recent advancement of studies on muscle oxygenation and oxidative metabolism. The Journal of Physiological Sciences, 69(1), 799-811. doi: 10.1007/s12576-019-00697-2

Hawkins, M. N., Raven, P. B., Snell, P. G., Stray-Gundersen, J., \& Levine, B. D. (2007). Maximal Oxygen Uptake as a Parametric Measure of Cardiorespiratory Capacity. Medicine \& Science in Sports \& Exercise, 39 (1), 103-107. doi: 10.1249/01.mss.0000241641.75101.64

Hearris, M. A., Hammond, K. M., Fell, J. M., \& Morton, J. P. (2018). Regulation of muscle glycogen metabolism during exercise: inplications for endurance performance and training adaptations. Nutrients, 10, 298. doi: $10.3390 /$ nu 10030298

Howley, E. T., Bassett, D. R., \& Welch, H. G. (1995). Criteria for maximal oxygen uptake: review and commentary. Medicine and Science in Sports and Exercise, 27(1), 1292-1292.

Humon io (2020). The Humon training zones. Retrieved 02/03, 2020, from https://humon.io/use-case/

Inglis, E.C., Iannetta, D., \& Murias, J. M. (2017). The plateau in the NIRS derived (HHb) signal near the end of a ramp incremental test does not indicate the upper limit of $\mathrm{O}_{2}$ extraction in the vastus lateralis. American Journal of Physiology Regulatory Integrative and Comparative Physiology, 313, R723-R729. doi: 10.1152/ajpregu.00261.2017

Karatzanos, E., Paradisis, G., Zacharogiannis, E., Tziortzis, S.,\& Nanas, S. (2010). Assessment of ventilatory threshold using near-infrared spectroscopy on the gastrocnemius muscle during treadmill running. International Journal of Industrial Ergonomics, 40, 206-211. doi: 10.1016/j.ergon.2009.02.003

Lam, Y. Y., \& Ravussin, E., (2016). Analysis of energy metabolism in humans: A review of methodologies. Molecular Metabolism, 5(11), 1057-1071. doi:10.1016/j.molmet.2016.09.005

Mocera, F., Aquilino, G., \& Somà, A. (2018). Nordic walking performance analysis with an integrated monitoring system. Sensors, 18(5), 1505. doi: 10.3390/s18051505

Murphy, M. H., Lahart, I., Carlin, A., \& Murtagh, E. (2019). The Effects of Continuous Compared to Accumulated Exercise on Health: A Meta-Analytic Review. Sports Medicine. 49(1), 1585-1607. doi: 10.1007/s40279-019-01145-2

Padulo, J., Iuliano, E., Dello Iacono, A., Milic, M., Rizzi, M., \& Ardigò, L. P. (2018). Nordic walking versus natural walking: an easy approach to comparing metabolic demands. International Journal of Performance Analysis in Sport, 18(5), 686-692. doi: 10.1080/24748668.2018.1514565

Pellegrin, B., Boccia, G., Zoppirolli, C., Rosa, R., Stella, F., Bortolan, L., ... Schena, F. (2018). Muscular 
and metabolic responses to different Nordic walking techniques, when style matters. PLoS ONE 13(4): e0195438. doi: 10.1371/journal.pone.019543

Seshadri, D. R., Li, R. T., Voos, J. E., Rowbottom, J. R., Alfes, C. M., Zorman C. A., \& Drummond, C. K. (2019). Wearable sensors for monitoring the internal and external workload of the athlete. NPJ Digital Medicine, 2(71). doi :10.1038/s41746-019-0149-2

Slaght, J., Sénéchal, M., Hrubeniuk, T. J., Mayo, A., \& Bouchard, D. R. (2017). Walking cadence to exercise at moderate intensity for adults: a systematic review. Journal of Sports Medicine, 4641203. doi: $10.1155 / 2017 / 4641203$.

Takaishi,T., Sugiura, T., Katayama, K., Sato, Y., Shima, N., Yamamoto, T., \& Moritani, T. (2002). Changes in blood volume and oxygenation level in a working muscle during a crank cycle. Medicine \& Science in Sports \& Exercise, 34(3), 520-528. doi: 10.1097/00005768-200203000-00020

Takeshima, N., Islam, M. M., Rogers, M. E., Rogers, N. L., Sengoku, N., Koizumi, D., ... Naruse, A. (2013). Effects of nordic walking compared to conventional walking and band-based resistance exercise on fitness in older adults. Journal of Sports Science and Medicine, 12, 422-430.

Tschentscher, M., Niederseer, D., \& Niebauer, J. (2013). Health benefits of Nordic walking: a systematic review. American Journal of Preventive Medicine. 44(1), 76-84. doi: 10.1016/j.amepre.2012.09.043

van der Zwaard, S., Jaspers, R. T., Blokland, I. J., Achterberg, C., Visser, J. M., den Uil, A.R., ... DE Ruiter, C.J. (2016). Oxygenation threshold derived from near-infrared spectroscopy: reliability and its relationship with the first ventilatory threshold. PLoS ONE, 11(9), e0162914. doi: 10.1371/journal.pone.0162914

Wewege, M. A., Thom, J. M., Rye, K. A., \& Parmenter, B. J. (2018). Aerobic, resistance or combined training: A systematic review and meta-analysis of exercise to reduce cardiovascular risk in adults with metabolic syndrome. Atherosclerosis, 274 (1), 162-171. doi: 10.1016/j.atherosclerosis.2018.05.002

Wilkinson, T. J, White, A. E. M., Nixon, D, G, D., Gould, D. W., Watson, E., L. \& Smith, A. C. (2019). Characterising skeletal muscle hemoglobin saturation during exercise using near-infrared spectroscopy in chronic kidney disease. Clinical and Experimental Nephrology 23, 32-42. doi: 10.1007/s10157-018$1612-0$

Yamamoto, J., Harada T., \& Okada, A. (2014). Difference in Physiological Components of $\mathrm{VO}_{2}$ Max during Incremental and Constant Exercise Protocols for the Cardiopulmonary Exercise Test. Journal of Physical Therapy Science, 26, 1283-1286. doi: 10.1589/jpts.26.1283 